\section{Salivary Diastases of the Frog and Toad}

Although the presence of diastatic enzymes in the saliva of frogs was originally announced by R. Lépine in $1870^{\prime}$ and confirmed by R. J. Junold in $1933^{2}$, its presence seems so largely to have escaped notice that a fresh investigation using newer techniques is not uncalled for, especially since neither author took the precaution of excluding bacterial enzymes, or made any attempt to determine the precise nature of the reactions involved.

The animals used in the present work were normal adult frogs and toads (no distinction was made as to the sex), which were killed by decapitation using a large pair of bone forceps, regurgitation from the stomach being thereby prevented. Four samples for testing were taken from the mouth of each animal, namely : (1) saline swabbings of the saliva, (2) the whole tongue, (3) scrapings of the mucosa of the palate, (4) the intermaxillary gland. Tissues from several animals were pooled and were incubated at room temperature $\left(c, 15^{\circ} \mathrm{C}\right.$.) for varying lengths of time. When tested against iodine the red-brown colour characteristic of erythrodextrins appeared in all cases. Bacterial activity was controlled, and it may be safely inferred that such diastatic activity as appeared was not due to bacterial enzymes.

The effect of $p H$ on this change from starch to erythrodextrin seems to be nil, since a series incubated at ten different values between 3.5 and 8.0 all gave the brown-red coloration within $30 \mathrm{~min}$. Again, no reducing sugars could be detected in any of the preparations.

When the extracts were incubated at $28^{\circ} \mathrm{C}$. no reducing sugars could be detected, even after $18 \mathrm{hr}$., when starch was used as a substrate; but a positive result was obtained in all cases except the mouth swabbings (which could scarcely have been other than very weak) when glycogen was employed. This complete hydrolysis of glycogen (unlike the starch reaction) is sensitive to changes in $p H$, and can be accomplished only in the range $p \mathrm{H} 4 \cdot 5-5 \cdot 5$, reduction being complete after $24 \mathrm{hr}$. under these conditions.

A partition chromatograph, kindly run for us by Dr. J. S. D. Bacon, of the Biochemistry Department of this University, confirmed the above results, and showed that, after $18 \mathrm{hr}$. incubation at $28^{\circ} \mathrm{C}$. with the enzymes contained in pooled tongue and intermaxillary-gland extract, hydrolysis went no further than maltose when starch was the substrate ; most of the polysaccharide still remained in the higher dextrin form. With glycogen as substrate a very similar picture was obtained, except that a trace of glucose was also present.

Although the above results point to the presence of a true dextrinogenic salivary enzyme, a further check was provided by testing the activity of similar extracts before and after dialysis. This made it clear that the enzymatic activity of the extracts can be inhibited by the removal of chloride ions and restored by their addition.

Four comparable samples taken from the toad (Bufo bufo L.) were incubated for $18 \mathrm{hr}$. at $28^{\circ} \mathrm{C}$. with both starch and glycogen substrates with a result similar to that obtained with the frog material, except that extracts of the tongue and intermaxillary gland of the toad both gave positive results when tested with Benedict solution, and it is presumed that the toad enzyme is more active or more plentiful.

It therefore appears that a true salivary amylase is present in these amphibians, although its functional significance is difficult to understand. The work is being continued with the view of elucidating this problem, as well as the wider questions of the phylogeny of salivary amylases and of the significance of buccal enzymes in general.

\section{E. T. B. Francis}

E. A. Ersa

Department of Zoology,

University of Sheffield. Oct. 13.

${ }^{1}$ Lépine, R., "Arb. physiol. Anstalt. Leipzig", 113 (1870).

'Junold, P. J., Inaug-diss. Leipzig (1933).

\section{A New Biometrical Phase Character in Locusts}

The solitary and the swarming phases of the same species of locusts can be distinguished by coloration and by biometrical characters ${ }^{1}$. Among the latter, the ratio $E / F^{\prime}$ of the elytron length $(E)$ to the posterior femur length $(F)$ has been generally used ${ }^{2}$, but no proper statistical investigation of the relative merits of various measurements and ratios exists. Careful measurements of all suitable parts of the body have now been undertaken on samples of the desert locust. Schistocerca gregaria (Forsk.), taken from wild populations of a very low density (phase solitaria), and from swarms (phase gregaria), and the data analysed statistically. None of the twenty direct measurements of body parts proved to be suitable, as the frequeney distribution polygons for the two phases overlapped widely. The $E / F$ ' ratios also showed an overlap which made its use uncertain. Moreover, a comparison of $E$ values in the two extreme phases showed that the elytron-length varied, according to the phase, in an opposite direction in the two sexes, thus :

$$
\begin{aligned}
& E \text { o gregaria }>E \text { o solitaria. } \\
& E \text { o gregaria }<E \text { o solitaria. }
\end{aligned}
$$

The fact that $E / F$ in gregaria is nevertheless greater than in solitaria in both sexes is due to a relatively greater phase variation in the $F$ values, which partly compensates for the irregularity of the variation in $E$.

A number of other ratios have been tested; but

\begin{tabular}{|c|c|c|c|c|c|c|c|c|c|c|c|c|}
\hline \multirow[t]{2}{*}{$F / C$} & \multicolumn{4}{|c|}{\begin{tabular}{l|l} 
Nomadacris septemfasciata Serv. \\
Male
\end{tabular}} & \multicolumn{4}{|c|}{$\begin{array}{l}\text { Schistocerca gregaria Forsk, } \\
\text { Male }\end{array}$} & \multicolumn{4}{|c|}{$\begin{array}{c}\text { Locusta migratoria migratorioides } \mathrm{R} . \& \mathrm{~F} \text {. } \\
\text { Male }\end{array}$} \\
\hline & Sol. & Greg. & Sol. & Greg. & Sol. & Greg. & Sol. & Greg. & Sol. & Greg. & Sol. & Greg. \\
\hline Mean & $3 \cdot 87$ & $3 \cdot 28$ & $3 \cdot 9 \theta$ & $3 \cdot 38$ & $3 \cdot 86$ & $3 \cdot 11$ & $3 \cdot 93$ & $3 \cdot 18$ & $3 \cdot 64$ & $2 \cdot 98$ & $3 \cdot 49$ & $2 \cdot 86$ \\
\hline error & \pm 0.018 & \pm 0.015 & \pm 0.018 & $\pm 0 \cdot 015$ & \pm 0.019 & \pm 0.009 & $\pm 0 \cdot 013$ & $\pm 0 \cdot 012$ & $\pm 0 \cdot 010$ & \pm 0.008 & \pm 0.011 & \pm 0.007 \\
\hline $\begin{array}{l}\text { deviation } \\
\text { Difference }\end{array}$ & $\pm 0 \cdot 103$ & $\pm 0 \cdot 123$ & $\pm 0 \cdot 107$ & $\pm 0 \cdot 107$ & $\pm 0 \cdot 137$ & $\pm 0 \cdot 094$ & $\pm 0 \cdot 140$ & $\pm 0 \cdot 102$ & $\pm 0 \cdot 106$ & \pm 0.085 & $\pm 0 \cdot 124$ & $\pm 0 \cdot 077$ \\
\hline $\begin{array}{l}\text { Detween } \\
\text { means } \\
d_{P} . f\end{array}$ & \multicolumn{2}{|c|}{$\begin{array}{l}0.59 \\
24.67 \\
102 \\
<0.001\end{array}$} & \multicolumn{2}{|c|}{ 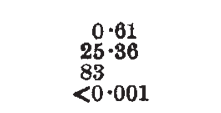 } & \multicolumn{2}{|c|}{$\begin{array}{c}0.75 \\
47 \cdot 68 \\
258 \\
<0 \cdot 001\end{array}$} & \multicolumn{2}{|c|}{$\begin{array}{l}\quad 0 \cdot 76 \\
35 \cdot 36 \\
215 \\
<0 \cdot 001\end{array}$} & \multicolumn{2}{|c|}{$\begin{array}{r}0 \cdot 66 \\
52 \cdot 23 \\
230 \\
<0 \cdot 001\end{array}$} & \multicolumn{2}{|c|}{$\begin{array}{c}0 \cdot 62 \\
47 \cdot 04 \\
246 \\
<0 \cdot 001\end{array}$} \\
\hline
\end{tabular}
all either showed an overlap, or were unsuitable for 